\title{
AN OVERVIEW ON THE BIOLOGICAL PERSPECTIVES OF AGLAIA SPECIES
}

\author{
PRIYA R, SOWMIYA P, MEENAKSHI SUNDARAM MUTHURAMAN*
}

Department of Biotechnology, School of Chemical and Biotechnology, SASTRA Deemed University, Thanjavur - 613 401 , Tamil Nadu, India. Email: msundar@biotech.sastra.edu

Received: 04 April 2018, Revised and Accepted: 29 May 2018

ABSTRACT

Medicinal plants have been identified and used throughout human history for treating various diseases. Plants belonging to genus Aglaia have been used in traditional system of medicine. The genus Aglaia is a member of Meliaceae family. The plants belonging to this genus have various biological activities including antipyretic, astringent, antidiarrheal, antidysenteric, anti-inflammatory, and anticancer activity and are also used in treating skin diseases and tumors. The phytochemistry and the various biological activities of Aglaia sp. such as anticancer, anti-inflammatory, antioxidant, antidiabetic, and nanoparticle activity are discussed in this review paper.

Keywords: Aglaia, Medicinal plants, Biological activity.

(c) 2018 The Authors. Published by Innovare Academic Sciences Pvt Ltd. This is an open access article under the CC BY license (http://creativecommons. org/licenses/by/4. 0/) DOI: http://dx.doi.org/10.22159/ajpcr.2018.v11i9.26436

\section{INTRODUCTION}

Plants provide the richest resource of natural compounds, which are used directly or indirectly for a wide range of applications for the well-being of human population and domestic animals [1]. These compounds are primarily phytomolecules synthesized through primary and secondary metabolic pathways in plants [2]. The dependence of humans on plants for their basic requirements such as food, medicine, clothes, and shelter is as old as mankind itself [3], and still in the modern age, the majority of commercial products including pharmaceutical and health care, food and beverages, textiles, cosmetics, and aromas are obtained from plants. Therefore, plants are and will remain economically, industrially, environmentally, spiritually, historically, and aesthetically important for survival, sustenance, and prosperity of life on the Earth. Since the early 1990s, the use of complementary and alternative medicine, including dietary supplements, has increased substantially. A benchmark national survey revealed that in the United States alone, use of any complementary and alternative medicine modality increased from 33.8\% in 1990 to $42.7 \%$ in 1997 [4]. A study conducted in 2002 found that $62 \%$ of those surveyed used some form of complementary and alternative medicine in the past 12 months [5]. Specifically, dietary supplement use has increased substantially, with herbal supplement use increasing more than the use of other complementary and alternative medicine modalities [6,7].

In the United States, in 2007 , about $38 \%$ of adults and $12 \%$ of children were using some form of traditional medicine. According to a survey by the National Center for Complementary and Alternative Medicine, herbal therapy or the usage of natural products other than vitamins and minerals was the most commonly used alternative medicine $(18.9 \%)[8,9]$. In India, herbal medicine is a common practice, and about 960 plant species are used by the Indian herbal industry, of which 178 are of a high volume, exceeding 100 metric tons per year [10]. At present, herbs are applied to the treatment of chronic and acute conditions and various ailments and problems such as cardiovascular disease, prostate problems, depression, inflammation, and to boost the immune system, and to name but a few. In China, in 2003, traditional herbal medicines played a prominent role in the strategy to contain and treat severe acute respiratory syndrome, and in Africa, a traditional herbal medicine, the Africa flower, has been used for decades to treat wasting symptoms associated with HIV [11,12].

The use of plants for healing purposes predates recorded history and forms the origin of much of modern medicine. Many conventional drugs originate from plant sources: A century ago, most of the few effective drugs were plant-based. Examples include aspirin (from willow bark), digoxin (from foxglove), quinine (from cinchona bark), and morphine (from the opium poppy). The development of drugs from plants continues, with drug companies engaged in the large-scale pharmacologic screening of herbs [13]. Over the past few decades, there has been a consistent raise in the number of diseases despite the high advancement in medicine [14]. Plants, on the other hand, have always been a vital source of the drug since the ancient times. They have been used due to their minimal toxic nature and are also highly biocompatible when compared with the harmful dosages of chemically synthesized drugs [15]. The family Meliaceae (=Mahogany family, order Sapindales) is an angiosperm plant family of mostly trees and shrubs together with a few herbaceous plants. This family includes about 50 genera and 550 species, with a pantropical geographical distribution [16].

Aglaia is a tree widely distributed in the tropical rainforests of Southeast Asia, Indonesia, and Malaysia. This genus Aglaia belongs to Meliaceae family. The plant is considered as a remedy for dysentery, skin diseases, leprosy, inflammation, leukoderma, and abdominal pain. It is said to have cooling effects and is useful in burning sensation of the body and painful micturition. The plant is a large tree with bright red wood; leaves shortly petiolate, pinnately compound having 5 (rarely 7 or 3 ) leaflets (Fig. 1), flowers shortly pedicellate (small, $0.2 \mathrm{~cm}$ in diameter), yellow (Fig. 2); fruits sub-globose small, and $0.25 \mathrm{~cm}$ in diameter.

Vernacular names of Aglaia

\begin{tabular}{ll}
\hline Languages & Common names \\
\hline Common name & Priyangu \\
Hindi & Priyangu \\
Tamil & Chokkala, chokkala \\
Malayalam & Nyalei, punniyava, cheeralam \\
Telugu & Yerra adugu, erranduga, kondanduga \\
Kannada & Gadagayya, kempu nola, thottilu, priyangu \\
\hline
\end{tabular}

\section{Phytochemical studies}

Balunas et al. have been successful in identifying numerous medicinal plants from tropical rainforest regions with potential anticancer activity. Silvesterol, a compound isolated from the chloroform extract of Aglaia foveolata proved to be cytotoxic to several human cancer cell lines [17]. Nugroho et al. isolated Rocaglamide compounds from fruit extract of Aglaia elliptica and leaves of Aglaia harmsiana. The isolated rocaglamide compounds exhibited strong insecticidal activity [18]. 


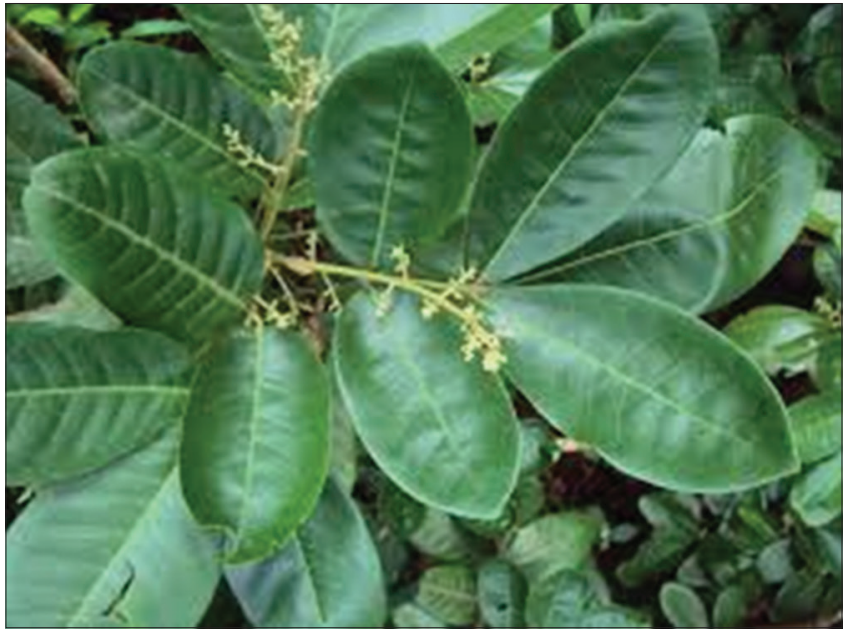

Fig. 1: Leaves of Aglaia

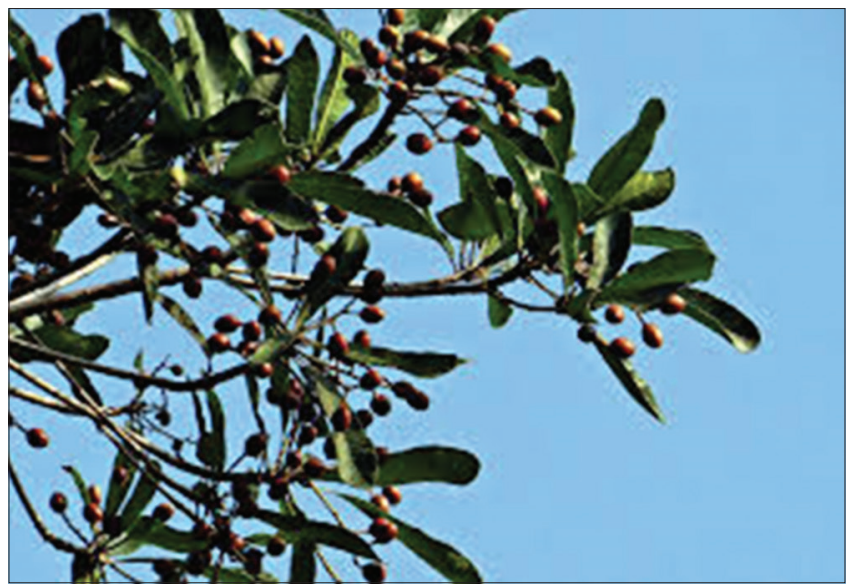

Fig. 2: Flowers of Aglaia

\section{Biological activity}

Anticancer activity

A phenolic ester isolated from leaves of Aglaia loheri was found to possess cytotoxic effects toward human CCRF-CEM leukemia cells and their drug-resistant sublime by reduction of the mitochondrial membrane potential and induction of apoptosis [19]. Chen et al. studied the Silvesterol isolated from the fruits and twigs of A. foveolata inhibits the cell growth and induces cell death in human MDA-MB-435 melanoma cells through the induction of caspase-mediated apoptosis [20]. Luan et al. confirmed that rocaglamide significantly sensitized the TRAIL-resistant HCC cells to apoptosis by TRAIL, which resulted from the Rocaglamide-mediated downregulation of cellular FLICE-like inhibitory protein and subsequent caspase-8 activations [21]. Li et al. studied the effects of rocaglamide-A (Roc-A) a component of Aglaia plant in osteoblast differentiation. Roc-A prevented TNF- $\alpha$-mediated inhibition of osteoblast differentiation and promoted direct osteoblast differentiation. It was found that Roc-A protected and stimulated osteoblast differentiation through blocking NF- $\mathrm{KB}$ pathway, suggesting that Roc-A may be a potential therapeutic drug for rheumatoid arthritis associated bone loss diseases blocking the NF- $\kappa B$ pathway [22]. Neumann et al. proved the natural component Roc-A (Rocaglamide-A) isolated from the medicinal plant Aglaia, induces phosphorylation of Cdc25A and its subsequent degradation thus blocking cell cycle progression of tumor cells at the G1-S Phase through the activation of the ATM/ATRChk1/Chk2 checkpoint pathway [23]. Kinghorn et al. reported that silvesterol and episilvesterol from Aglaia flaveolata are anticancer agents [24]. Silvesterol, a potential anticancer rocaglate derivative from A. foveolata, induced apoptosis in LNCaP (hormone-dependent human prostate cancer) cells through the mitochondrial/apoptosome pathway without any involvement of executioner caspase-3 or -7 [25].

Pan et al. studied cytotoxic effects of two minor silvesterol analogs and other new constituents 21-norbaccharane-type triterpene, 3,4-seco-dammarane triterpenes, eudesmane sesquiterpene, as well as nine known compounds isolated from a chloroform soluble fraction of A. foveolata and compared their cytotoxicity against HT-29 cell [26]. Kinghorn et al. investigated rocaglate derivatives of Aglaia and compounds from other higher plants for cytotoxic effects against cancer cells [27]. Pan et al. reported that ethanol extract of twigs, leaves and fruits and roots of Aglaia has cytotoxicity against HT-29 human colon cancer cell line [28]. Pan et al. isolated 8 new compounds and 16 existing compounds including silvesterol from methanol extracts of Aglaia perviridis and tested their cytotoxicity against HT-29 human colon cancer cell line. Seven rocaglate derivatives had potent cytotoxic effects on HT-29 cell lines [29]. Ebada et al. confirmed Rocaglamides (Flavaglines) and other constituents are from Aglaia species have potent anticancer, antifungal, and antibacterial activities [30].

Nuraqilah Othman et al. focused on silvesterol and other new compounds isolated from the methanol extract of the stems of Aglaia stellatopilosa, and tested their cytotoxicity against three human cancer cell lines, and the compounds were also tested for antimicrobial activity against bacteria and fungi [31]. Kinghorn et al. summarized the discovery of anticancer agents from aquatic and terrestrial cyanobacteria, tropical plants and filamentous fungi and stated that plant-derived compounds of Aglaia are studied for anticancer activity for human cancer [32]. Cencic et al. evaluated anticancer activity of Aglaia derived silvesterol compound. It was found that silvesterol exhibits anticancer activity in human breast and prostate cancer xenograft models and that this is associated with increased apoptosis, decreased proliferation, and inhibition of angiogenesis. It was proposed that silvesterol mediates its effects by preferentially inhibiting translation of malignancyrelated mRNAs [33]. Leong et al. investigated the plant-derived single compound cycloartane isolated from hexane extract of Aglaia exima leaves and reported that cycloartane reduces the viability of colon cancer cell line through the activation of caspase 8 and 9 and caspase-3/7, PARP cleavage and the lack of NFkB translocation into the nucleus. Leading to apoptosis [34].

\section{Antidiabetic activity}

Sun et al. confirmed prenylated bibenzyls named aglaiabbrevins A-D isolated from the leaves of Aglaia abbriviata inhibits protein tyrosine phosphatase-1B (PTP1B). These prenylated bibenzyls may be considered as lead compounds for the development of new antiobesity and antidiabetic agents [35].

\section{Anti-inflammatory activity}

Liu et al. derived anti-inflammatory activity and other antioxidant, antimicrobial activities from the medicinal plants honey, made from different floral sources. Floral honey from Aglaia formosana was involved in testing of anti-inflammatory activity.[36]. Yodsaoue et al. evaluated triterpenoids and triterpenoids compounds isolated from the leaf extract of Aglaia odorata and tested the anti-inflammatory activity by the inhibition of lipopolysaccharide-induced nitric oxide production in RAW264.7 cell lines [37]. Janaki et al. studied alcoholic extract of fruits and aerial portion of Aglaia roxburghiana var. beddomei extract and triterpenes roxburghiadiol A and B isolated and tested and observed anti-inflammatory activity [38].

\section{Antioxidant activity}

Liu et al. evaluated floral honey from A. formosana for antioxidant, antimicrobial, and anti-inflammatory activity and isolated protein, flavonoids and phenolic compounds having antioxidant, and other activities [36].

\section{Nanoparticle synthesis}

Manjari et al. proved phytogenic synthesis of recyclable copper oxide nanoparticles, from flower extracts of Aglaia elaeagnoidea 
possess great prospects in reduction of pernicious dyes and nitro organic pollutants in water [39]. Gangarapu et al. synthesized silver nanoparticles from the leaf extract of A. elaeagnoidea using it as a reducing, capping, and stabilizing agent. The synthesized AgNP was embedded in natural polymer alginate. The preparation of $\mathrm{Ag}-\mathrm{CA}$ composite was facile, stable, efficient, eco-friendly, easy to recycle, non-toxic, and cost effective for commercial application [40]. Benelli et al. used an aqueous extract of A. elaeagnoidea, for synthesizing silver nanoparticles that were toxic to Culex quinquefasciatus, Aedes aegypti, and Anopheles stephensi mosquitoes [41]. Copper oxide sodium alginate nanocomposite prepared from leaf extract of A. elaeagnoidea.

The produced copper oxide sodium alginate nanocomposite was used as a catalyst for the reduction of 4-Nitrophenol in the liquid phase [42]. Antioxidant and catalytic property of synthesized gold and silver nanoparticles from the flower extract of A. elaeagnoidea were evaluated by Manjari et al. The study proved that the synthesized nanoparticles have ultra-rapid catalytic properties [43].

\section{CONCLUSION}

Plant is one of the most important sources for medicine. WHO portrayed that about $80 \%$ of the world's population believes in the ancient and traditional plant-based treatment for different ailments [44]. Medicinal plants play a key role in Indian traditional medicine. The plants of genus Aglaia have been used traditionally and are scientifically reported to have antioxidant, antimicrobial, anticancer, and anti-inflammatory activities. Till date, a large number of herbal products has been screened for their biomedical applications through various experimental models. This has caused the discovery of the several drugs by the pharmaceutical and scientific communities [45].

\section{ACKNOWLEDGMENT}

The authors would like to thank the Management, SASTRA Deemed University for providing the necessary facilities. Meenakshi Sundaram M gratefully acknowledges Prof. TRR research grant from SASTRA Deemed university and EMR grant (Z.28015/07/2018-HPC(EMR)-AYUSH-E) from Ministry of AYUSH.

\section{AUTHORS' CONTRIBUTION}

All authors equally contributed to the preparation of the manuscript.

\section{CONFLICTS OF INTEREST}

None.

\section{REFERENCES}

1. Khanuja SP. Functional diversity of plant metabolome and microbiome in health services to the human life. Proc Natl Acad Sci India Sect B Biol Sci 2012;82:291-4.

2. Arora DS, Onsare JG, Kaur H. Bioprospecting of Moringa (Moringaceae): Microbiological perspective. J Pharmacogn Phytochem 2013;1:193-215

3. Goyal BR, Agrawal BB, Goyal RK, Mehta AA. Phyto-pharmacology of Moringa oleifera Lam.: An overview. Nat Prod Radiance 2007;6:347-53.

4. Eisenberg DM, Davis RB, Ettner SL, Appel S, Wilkey S, Van Rompay M, et al. Trends in alternative medicine use in the United States, 1990-1997: Results of a follow-up national survey. JAMA 1998;280:1569-75

5. Barnes PM, Powell-Griner E, McFann K, Nahin RL. Complementary and alternative medicine use among adults: United States, 2002. Advance Data from Vital and Health Statistics, No. 343. Hyattsville, MD: National Center for Health Statistics; 2004.

6. Slesinski MJ, Subar AF, Kahle LL. Trends in use of vitamin and mineral supplements in the United States: The 1987 and 1992 National Health Interview Surveys. J Am Diet Assoc 1995;95:921-3.

7. Millen AE, Dodd KW, Subar AF. Use of vitamin, mineral, nonvitamin, and nonmineral supplements in the United States: The 1987, 1992, and 2000 National Health Interview Survey results. J Am Diet Assoc 2004;104:942-50.

8. Ernst E, Schmidt K, Wider B. CAM research in Britain: The last
10 years. Complement Ther Clin Pract 2005;11:17-20.

9. Barnes PM, Bloom B, Nahin R. Complementary and alternative medicine use among adults and children: United States, 2007. CDC National Health Statistics Report \#12; 2008.

10. Sahoo N, Manchikanti P, Dey S. Herbal drugs: Standards and regulation. Fitoterapia 2010;81:462-71.

11. De Smet P. Herbal medicine in Europe: Relaxing regulatory standards. N Engl J Med 2005;352:1176-8.

12. Tilburt JC, Kaptchuk TJ. Herbal medicine research and global health: An ethical analysis. Bull World Health Organ 2008;86:594-9.

13. Vickers A, Zolliman C, Lee R. The ABC of complementary medicine: Herbal medicine. Br Med J 1999;319:1050-3.

14. Morse SS. Factors in the emergence of infectious diseases. Emerg Infect Dis 1995;1:7-15.

15. Handa SS, Sharma A, Chakroborty KK. Natural products and plants as liver protecting drug. Fitoterapia 1986;57:307-51.

16. Ebada SS, Lajkiewicz N, Porco JA Jr, Li-Weber M, Proksch P, Falk AD, et al., editors. Progress in the Chemistry of Organic Natural Products. Vol. 94. Vienna: Springer-Verlag Wien; 2011.

17. Balunas MJ, Kinghorn AD. Drug discovery from medicinal plants. Life Sci 2005;78:431-41

18. Nugroho BW, Ssregen BG, Wray V, Witte TL, Bringmann G, Proksch P. Insecticidal rocaglamide derivatives from Aglaia elliptica And A. harmsina. Phytochemistry 1997;45:1579-85.

19. Dapat E, Jacinto S, Efferth T. A phenolic ester from Aglaia loheri leaves reveals cytotoxicity towards sensitive and multidrug-resistant cancer cells. BMC Complement Altern Med 2013;13:286.

20. Chen WL, Pan L, Kinghorn AD, Swanson SM, Burdette JE. Silvestrol induces early autophagy and apoptosis in human melanoma cells. BMC Cancer 2016;16:17.

21. Luan Z, He Y, He F, Chen Z. Rocaglamide overcomes tumor necrosis factor-related apoptosis-inducing ligand resistance in hepatocellular carcinoma cells by attenuating the inhibition of caspase-8 through cellular FLICE-like-inhibitory protein down regulation. Mol Med Rep 2015;11:203-11.

22. Li A, Yang L, Geng X, Peng X, Lu T, Deng Y, et al. Rocaglamide - A potentiates osteoblast differentiation by inhibiting NF-Kb signaling. Mol Cells 2015;38:941-9.

23. Neumann J, Boerries M, Kohler R, Giaisi M, Krammer PH, Busch H, et al. The natural anticancer compound rocaglamide selectively inhibits the G1-S-phase transition in cancer cells through the ATM/ATR-mediated Chk1/2 cell cycle checkpoints. Int J Cancer 2014;134:1991-2002.

24. Kinghorn AD, De Blanco EJ, Chai HB, Orjala J, Farnsworth NR, Doel Soejarto D, et al. Discovery of anticancer agents of diverse natural origin. Pure Appl Chem 2009;81:1051-63.

25. Kim S, Hwang BY, Su BN, Chai H, Mi Q, Kinghorn AD, et al. Silvestrol, a potential anticancer rocaglate derivative from Aglaia foveolata, induces apoptosis in lncap cells through the mitochondrial/ apoptosome pathway without activation of executioner caspase- 3 or -7 . Anticancer Res 2007;27:2175-83.

26. Pan L, Kardono LB, Riswan S, Chai H, De Blanco EJ, Pannell CM, et al. Isolation and characterization of minor analogues of silvesterol and other constituents from a large-scale recollection of Aglaia foveolata. J Nat Prod 2010;73:1873-8.

27. Kinghorn AD, Pan L, Fletcher JN, Chai H. The relevance of higher plants in lead compound discovery programs. J Nat Prod 2011;74:1539-55.

28. Pan L, Chai HB, Kinghorn AD. Discovery of new anticancer agents from higher plants. Front Biosci (Sch Ed) 2013;4:142-56.

29. Pan L, Acuna UM, Li J, Jena N, Ninh TN, Pannell CM, et al. Bioactive flavaglines and other constituents isolated from Aglaia perviridis. J Nat Prod 2013;76:394-404.

30. Ebada SS, Lajkiewicz N, Porco JA Jr, Li-Weber M, Proksch P. Chemistry and biology of rocaglamides (=flavaglines) and related derivatives from Aglaia species (Meliaceae). Prog Chem Org Nat Prod 2011;94:1-58.

31. Othman N, Pan L, Mejin M, Voong JC, Chai HB, Pannell CM, et al. Cyclopenta $[B]$ benzofuran and secodammarane derivatives from the stems of Aglaia stellatopilosa. J Nat Prod 2016;79:784-91.

32. Kinghorn AD, De Blanco EJ, Lucas DM, Rakotondraibe HL, Orjala J. Discovery of anticancer agents of diverse natural origin. Anticancer Res 2016:36:5623-37.

33. Cencic R, Carrier M, Galicia-Va'Zquez G, Bordeleau ME, Sukarieh R, Bourdeau A, et al. Antitumor activity and mechanism of action of the cyclopenta[B]benzofuran, silvestrol. Eif4a as anti-cancer target. PLoS One 2009:4:5223.

34. Leong KH, Looi CY, Loong XM, Cheah FK, Supratman U, Litaudon M, et al. Cycloart-24-Ene-26-Ol-3-one, a new cycloartane isolated from 
leaves of Aglaia exima triggers tumour necrosis factor-receptor 1-mediated caspase-dependent apoptosis in colon cancer cell line. New cycloartane triggers TNFR-1 apoptosis in colon cancer cell line. PLoS One 2016;11:e0152652.

35. Sun P, Jiang CS, Zhang Y, Liu AH, Liang TJ, Li J, et al.Aglaiabbrevins A-D, new prenylated bibenzyls from the leaves of Aglaia abbreviata with potent PTP1B inhibitory activity. Chem Pharm Bull 2017;65:295-9.

36. Liu JR, Ye YL, Lin TY, Wang YW, Peng CC. Effect of floral sources on the antioxidant, antimicrobial, and anti-inflammatory activities of honeys in Taiwan. Food Chem 2013;139:938-43.

37. Yodsaoue O, Sonprasit J, Karalai C, Ponglimanont C, Tewtrakul S, Chantrapromma S. Diterpenoids and triterpenoids with potential anti-inflammatory activity from the leaves of Aglaia odorata. Phytochemistry 2012;76:83-91.

38. Janaki AS, Vijayasekaran AV, Viswanathan AS, Balakrishna K. Antiinflammatory activity of Aglaia roxburghiana Var. Beddomei extract and triterpenes Roxburghiadiol A and B. J Ethnopharmacol 1999;67:45-51.

39. Manjari G, Saran S, Arun T, Rao AV, Devipriya SP. Catalytic and recyclability properties of phytogenic copper oxide nanoparticles derived from Aglaia elaeagnoidea flower extract. J Saudi Chem Soc 2017;21:610-8.
40. Gangarapu M, Sarangapany S, Veerabhali KK, Devipriya SP, Arava VB. A high-performance catalytic and recyclability of phytosynthesized silver nanoparticles embedded in natural polymer. J Clust Sci 2017;2017:265864

41. Benelli G, Govindarajan M, Senthilmurugan S, Vijayan P, Kadaikunnan $\mathrm{S}$, Alharbi NS, et al. Fabrication of highly effective mosquito nanolarvicides using an Asian plant of ethno-pharmacological interest priyangu (Aglaia elaeagnoidea): Toxicity on non-target mosquito natural enemies. Environ Sci Pollut Res Int 2018;25:10283-93.

42. Gangarapu M, Arava VR. Copper nanoparticles encapsulated alginate composite for reduction of aromatic nitro compounds. Int J Sci Eng Res 2017;8:732-5

43. Manjari G, Saran S, Arun T, Devipriya SP, Rao AV. Facile Aglaia elaeagnoidea mediated synthesis of silver and gold nanoparticles: Antioxidant and catalysis properties. J Clust Sci 2017;8:2041-56.

44. Nithya S, Muthuraman MS. An overview on the biological perspectives of Nardostachys jatamansi DC. Int J Pharm Pharm Sci 2016;8:31-6.

45. Sujana N, Ramanathan S, Vimala V, Muthuraman MS, Pemaiah B. Antitumour potential of Passiflora incarnata. L against Ehrlich ascites carcinoma. Int J Pharm Pharm Sci 2012;4:17-20. 